\title{
PROTAGONISMO FEMININO EM BIOGRAFIAS: PERSPECTIVAS DE GÊNERO NA CONSTRUÇÃO DAS PERSONAGENS ELIS REGINA E MARIA BONITA'
}

\author{
FEMALE PROTAGONISM IN BIOGRAPHIES: GENDER PERSPECTIVES IN THE CONSTRUCTION OF THE \\ CHARACTERS ELIS REGINA AND MARIA BONITA
}

\section{RESUMO}

O objetivo deste trabalho é analisar aspectos relativos às representações de gênero na construção das personagens nas biografias de duas mulheres: Furacão Elis (2012), escrita pela jornalista Regina Echeverría e Maria Bonita: Sexo, violência e mulheres no cangaço (2018), da jornalista Adriana Negreiros. O artigo traça um histórico do segmento biográfico, bem como do pioneirismo de suas publicações no Brasil; pontua a contribuição feminina no jornalismo e na literatura e, ainda, percorre a caracterização das personagens na ficção brasileira, de modo a demarcar o processo de inserção das mulheres no campo literário, seja como autoras ou como personagens. Com base em uma revisão bibliográfica a partir dos conceitos de patriarcado (LERNER, 1990), feminismo negro (CARNEIRO, 2002; DAVIS, 2016), maternidade (BADINTER, 1981; DONATH, 2017) e independência feminina (WELZER-LANG, 2001), infere-se que as mulheres carregam estereótipos não apenas na ficção, mas também quando suas trajetórias são recontadas em obras biográficas.

Palavras-chave: Jornalismo. Biografias. Protagonistas mulheres. Gênero.

\begin{abstract}
The goal of this article is to analyze aspects of representation of gender in the construction of characters in the biographies of two women: Furacão Elis (2012), written by the journalist Regina Echeverría, and Maria Bonita: Sexo, violência e mulheres no cangaço (2018), by the journalist Adriana Negreiros. This work traces a history of the biographical segment, and also the pioneering of its publications in Brazil; points out the contribution of women in journalism and literature, and in addition traces the characterization of characters in Brazilian fiction in order to demarcate the process of insertion of women in the literary field, as characters or either as authors. In a bibliographical review based on the concepts of patriarchy (LERNER, 1990), black feminism (CARNEIRO, 2002; DAVIS, 2016), maternity (BADINTER 1981; DONATH, 2017), and female independence (WELZER-LANG, 2001), the conclusion
\end{abstract}

1 Versão atualizada do artigo apresentado ao VI Colóquio Mulher e Sociedade, promovido pelo Programa de Pós-Graduação (Mestrado) em Jornalismo da Universidade Estadual de Ponta Grossa (UEPG) nos dias 23 e 24 de abril de 2019.

Karina J. Woitowicz

UEPG. Email: karinajw@gmail.com

Felipe Adam

Pontifícia Universidade Católica do Rio Grande do Sul (PUC-RS/Brasil). Email: felipeadam91@gmail.com 
is that women carry stereotypes not only in fiction, but also when their trajectories are recounted in biographical works.

Key-words: Journalism. Biographies. Women protagonists.Gender.

\section{Introdução}

Em 2018, o mercado editorial no segmento biográfico recebeu duas obras assinadas por jornalistas mulheres: em agosto, Maria Bonita: Sexo, violência e mulheres no cangaço, da paulista Adriana Negreiros e em novembro, Jorge Amado: Uma biografia, da baiana Josélia Aguiar. Em ambos os livros, a trajetória é narrada levando em conta o local de fala: no primeiro caso, em especial, a história do cangaço é recontada por uma mulher a partir da protagonista Maria Bonita - ao invés da figura de Virgulino Ferreira da Silva, o mítico Lampião.

No campo de produção de livros-reportagem, as jornalistas possuem identificação. Dois exemplos recentes de reconhecimento são Eliane Brum²(2006, 2008) e Daniela Arbex 3 (2013, 2015, 2018). Em âmbito internacional, a valorização por esse tipo de trabalho chegou tarde, como conta Alexandre Maciel (2018):

Em termos internacionais, o campo da não ficção em livro comemorou o prêmio Nobel de Literatura de 2015, concedido, pela primeira vez, a uma autora de livros-reportagem, a escritora e jornalista bielorussa Svetlana Alexiévitch, que concebeu, entre outras obras, Vozes de Tchernóbil: a história oral de um desastre e A guerra não tem rosto de mulher, lançados em 2016 no Brasil. Um sinal de reconhecimento do gênero no campo literário e no mercado editorial. (MACIEL, 2018: 133).

Porém, no campo da Biografia, o prestígio ainda caminha a passos lentos. Para ilustrar a representatividade de profissionais biógrafas em premiações de destaque no país, em 13 anos do segmento Biografia no Prêmio Jabuti de Literatura, nunca uma jornalista ficou entre os três primeiros lugares. Aliás, apenas uma mulher conquistou o prêmio: a historiadora Lilian Moritz Schwarcz, em 2009, com o livro O sol do Brasil, que reconta a trajetória do pintor Nicolas-Antoine Taunay. Além disso, em 2006, no ano em que o gênero recebeu destaque isolado pela primeira vez na premiação, a

2 Em janeiro de 2019, a jornalista gaúcha Eliane Brum, colunista do El País Brasil, recebeu a menção de +Premiada Jornalista da História do Brasil. Disponível em: https://www.portaldosjornalistas. com.br/eliane-brum-segue-como-a-premiada-jornalista-da-historia/?fbclid=IwAR3nByThPAAMMAo4TqFI4z8OXvqjnIL-SWFy5jFa1KbQr9FFvh5SrKwveY. Acessado em 27 jan. 2019.

3 A jornalista mineira Daniela Arbex também coleciona premiações. Holocausto brasileiro, por exemplo, foi eleito Melhor Livro-Reportagem do Ano pela Associação Paulista de Críticos de Arte (2013) e segundo melhor Livro-Reportagem no prêmio Jabuti (2014). Disponível em: http://www.danielaarbex.com.br/ sobre-mim/. Acessado em 29 jan. 2019. 
obra laureada foi Carmen: Uma biografia, escrita pelo jornalista Ruy Castro. Porém, seria a última vez que uma biografada receberia o troféu.

Neste trabalho, o objetivo é analisar como duas protagonistas foram representadas por duas mulheres jornalistas em períodos diferentes. Ou seja, desde a primeira publicação de uma biografia por uma jornalista- Furacão Elis, em 1985, da então estreante Regina Echeverría -até agosto de 2018, com o lançamento de Maria Bonita: Sexo, violência e mulheres no cangaço, de Adriana Negreiros. Para isso, serão avaliados quatro critérios baseados em aportes oriundos dos estudos de gênero: o patriarcado, o feminismo negro, a maternidade e a independência feminina.

$\mathrm{O}$ artigo se organiza a partir de uma estrutura que parte do desenvolvimento do biografismo jornalístico no Brasil para, no tópico seguinte, situar brevemente a presença e a participação das mulheres na imprensa, trazendo características de Rachel de Queiroz e de Patrícia Galvão como personagens emblemáticas que atuaram no jornalismo. Com base neste percurso, realiza-se o estudo das personagens biografadas por mulheres jornalistas, levando-se em conta as pesquisas relacionadas ao estudo de gênero, como Lerner (1990), Carneiro (2002), Davis (2016), Badinter (1981) e Donath (2017).

\section{Trajetória do biografismo no Brasil}

O gênero Biografia vive num tensionamento de fronteiras, limites estes que se esbarram ora na História, ora na Literatura e mais recentemente, no campo do Jornalismo. Aliás, desde os anos 1930, a biografia no Brasil se tornou um segmento de leitura apreciado. "Foi a época da voga brasileira de Stefan Zweig, de Emil Ludwig e de Van Loon, os três embarcando na conjuntura favorável a uma linha de divulgação de bom nível" (GALVÃO, 2005: 363), período marcado por um surto editorial; porém, de biografias traduzidas.

Entre os precursores brasileiros, destacam-se as figuras de historiadores como Pedro Calmon e Luís Vianna Filho. Contudo, foi com Elói Pontes ${ }^{4}$ e, especialmente, Raimundo Magalhães $\mathrm{Jr}^{5}$, que a biografia seria também abraçada pelos jornalistas. Ensaísta, teatrólogo, tradutor e ainda jornalista, Magalhães Jr modernizou o gênero e contribuiu para a evolução do biografismo. Segundo Mariza Andrade (2013: 17), “(...) suas biografias apresentam um sentimento de 'pertença ao nacional', ou seja, o autor parece apostar na ideia de que é preciso dar a conhecer a vida e a obra daqueles que trabalharam, no século XIX, pela construção da nação brasileira”.

Em 1981, Raimundo Magalhães Jr falece aos 74 anos. Com sua morte, estudiosos previam um vácuo de produção no segmento que ele mesmo ajudou

4 Escreveu: A vida inquieta de Raul Pompéia (1935), A vida dramática de Euclides da Cunha (1938), A vida contraditória de Machado de Assis (1939), A vida exuberante de Olavo Bilac (1944) (VIEIRA, 2015).

5 Três panfletários do Segundo Império (1956), Dom Pedro II e a condessa de Barral (1956), Deodoro - a espada contra o Império (1957), Rui, o homem e o mito (1965) estão entre suas principais obras (VIEIRA, 2015). 
a construir. Ao contrário do que se esperava, a década de 1980 seria o período em que os jornalistas começariam a ter gosto pelo segmento, dando luz a uma nova fase do biografismo. "Dois traços definem os inícios do novo biografismo: em primeiro lugar, versaria as vidas ou de brasileiros ou de pessoas de interesse crucial para a história do Brasil, pouco divulgadas; em segundo, defenderia causas progressistas" (GALVÃO, 2005:356). O carioca Alberto Dines foi quem deu início, em 1981, a essa trajetória bem sucedida dos profissionais pela vereda biográfica. O seu Morte no paraíso: A tragédia de Stefan Zweigse propõe a recontar a vida do também biógrafo austríaco, que se suicidou em Petrópolis nos anos 1940. O mercado livreiro presenciaria, quatro anos depois, mais dois lançamentos: em 1985, o mineiro Fernando Morais publicava Olga-obra que permaneceu 29 meses na lista dos livros mais vendidos, considerado "o maior best-seller jornalístico do Brasil de 1966 a 2004" (CATALÃO JR, 2010: 108) e que relata a vida de Olga Benário Prestes, companheira de Luís Carlos Prestes - e a paulista Regina Echeverría, o seu Furacão Elis -a respeito da cantora gaúcha Elis Regina.

O boom de vendagem aconteceria na década de 1990, com sucessivos lançamentos ${ }^{6}$ : os cariocas Carlos Didier e João Máximo publicavam Noel Rosa: Uma biografia (1990), mas se depararam com problemas junto aos parentes do exsambista. Em 1992, o mineiro Ruy Castro lançava $O$ anjo pornográfico; dois anos depois, Fernando Morais e Chatô: o Rei do Brasil, bem como Marcel Souto Maior e As vidas de Chico Xavier. O ano de 1995 marcaria o jornalismo pelas publicações de duas obras: Mauá: Empresário do Império, do paulista Jorge Caldeira e Estrela solitária: Um brasileiro chamado Garrincha, de Ruy Castro.

Atualmente, as biografias e todo o grande grupo de narrativas biográficas - formado por cartas, diários, memórias, perfis - se consolidaram como um nicho de produção e vendagem no mercado editorial brasileiro. De 2016 para 2017, por exemplo, a temática Biografias evoluiu 11,14\% no campo da produção de acordo com pesquisa encomendada pela Câmara Brasileira do Livro (CBL), Sindicato Nacional dos Editores de Livros (SNEL) e Fundação Instituto de Pesquisas Econômicas (Fipe). Porém, antes de refletir sobre a participação das jornalistas na produção biográfica, é válido compreender o contexto em que se deu a aproximação da mulher com a leitura, sua contribuição textual nos jornais e o espaço dedicado à literatura.

\section{Pioneirismo das mulheres nas redações}

1904. Quando João do Rio elaborou a pergunta "O jornalismo, especialmente no Brasil, é um fator bom ou mau para a arte literária?” (COSTA, 2005: 11) e a encaminhou para mais de cem pessoas - destes, 36 retornaram, entre eles nenhuma mulher - o então jornalista tinha a intenção de fazer uma radiografia da vida literária

6 Chatô (205 mil exemplares), Mauá (106 mil) e Estrela solitária (76 mil) lideraram a vendagem dos livros de não-ficção em novembro de 1995. Os dados foram fornecidos pela editora Companhia das Letras, relacionados às vendas realizadas até março de 2001 (VILAS BOAS, 2002). 
no início do século XX. Mais de cem anos depois, o texto se tornou um documento fundamental para a história da literatura e imprensa brasileiras. De acordo com pesquisa de Cristiane Costa (2005), esse contexto pode ser dividido em cinco períodos: o primeiro, de 1808 a 1830; a segunda etapa, que vai de 1840 a 1910; a terceira época discute a era da modernização entre 1920 e 1950; o quarto sustenta de 1960 a 1980 e o quinto vai de 1980 a 2004. "Com a modernização da indústria editorial brasileira, surge uma literatura de mercado que já ousa dizer seu nome, praticamente por autores como Benjamin Costallat, Monteiro Lobato, Erico Verissimo e Jorge Amado, todos eles best-sellers com experiência prévia na imprensa" (COSTA, 2005: 14).

No campo da produção literária, que entre o final do século XIX e início do XX mantinha aproximação com o jornalismo, percebe-se um processo de apagamento da participação das mulheres, que chegavam inclusive a publicar seus escritos com pseudônimos masculinos, reconhecendo a existência de lugares proibidos a elas. Perrot (2005) destaca que o silêncio foi reiterado através dos tempos pelas religiões, pelos sistemas políticos e pelos manuais de comportamento: "aceitar, conformarse, obedecer, submeter-se e calar-se. Este mesmo silêncio, imposto pela ordem simbólica, não é somente o silêncio da fala, mas também o da expressão, gestual ou escrituraria" (PERROT, 2005: 10).

Sabe-se que o surgimento da imprensa feita por mulheres acontece ainda no século XIX (DUARTE, 2016; MUZART, 2003), com a publicação de jornais que discutiam principalmente a participação política das mulheres, o direito à educação e as mudanças de costumes. Contraditoriamente, no mesmo momento em que surgiam publicações voltadas ao público feminino, que se ocupavam de assuntos como moda, culinária e cuidados domésticos, também eram criados espaços que problematizavam a 'condição da mulher' e reivindicavam sua participação na vida pública.

Na década de 1920, embora as mulheres convivessem com práticas de controle por parte dos pais, irmãos ou maridos, surgem alguns movimentos nos centros urbanos com o intuito de problematizar sua participação política e social. Neste contexto, registra-se como marco a efervescência cultural motivada pela Semana de Arte Moderna - realizada na cidade de São Paulo em fevereiro de 1922 - e o ato de leitura, em salões, de maneira individual ou em grupos, em voz alta, que fomentava um aspecto importante da vida familiar. Nessa época, os jornais eram peça chave da construção social e, para que fossem ouvidas, as mulheres defendiam seus espaços por meio da atividade da imprensa.

Entretanto, grande parte das publicações era pouco politizada, com foco em afazeres domésticos. "Além da função de informar à mulher, notadamente da classe média, sobre assuntos femininos, enfatizava as notícias sobre moda, literatura, poesia, folhetins" (CARVALHO, 1995: 5-6). O autor ainda destaca o papel das pioneiras no jornalismo:

A colaboração feminina teve início pela literatura, pelo conto, romance e poesia. Algumas mulheres se destacaram como Júlia 
Lopes de Almeida, Corina Coaraci, Carmem Dolores, Gilka Machado. Entretanto, vale lembrar que a primeira repórter, Eugenia Brandão, foi admitida em 1914 na revista A Rua, que circulou de 1911 a 1922. (CARVALHO, 1995: 7).

Na literatura, Rachel de Queiroz, Cecília Meirelles e Clarice Lispector foram mulheres que conquistaram reconhecimento em seus trabalhos de ficção - basta analisar O quinze, O romanceiro da inconfidência e A hora da estrela, respectivamente. Porém, antes disso, o trio exerceu o trabalho de jornalistas. Bulhões e Sobral (2017), por exemplo, retratam como Rachel de Queiroz se aproximou do ofício:

Era a fazenda Junco de onde, futuramente, passando férias, enviaria a sua coluna semanal para a revista $O$ Cruzeiro. Futuramente a menina Rachel colaboraria para a revista, numa longa permanência que vai de 1944 a 1975. Mas antes disso é preciso que se diga que começou, naquele tempo da mocidade, no jornal O Ceará, no tempo em que era prática o uso de pseudônimos e o que escolheu no momento foi Rita de Queluz. Durante toda a sua vida, nas oportunidades que se apresentavam, gostava sempre de dizer que, mais que romancista e escritora, era jornalista. (BULHÕES; SOBRAL, 2017: 40).

Contemporânea das profissionais acima relatadas, Patrícia Rehder Galvão, conhecida pela alcunha de Pagu, também fez história na primeira metade do século XX. "O que caracteriza o seu jornalismo é uma participação ativa na vida paulistana, e, mais tarde, santista, além da capacidade de expressar ideias e sentimentos em prosa sucinta e sintética, baseada em observações ou experiências pessoais" (JACKSON, 2011:34). Seu jornalismo se inicia aos 18 anos como desenhista; mais tarde migra para coluna e ainda flerta com a crônica. Sua admiração pela escrita foi intensa por viver num paralelo com o mundo social, influenciada por correntes históricas e fases de vida. "Desde as primeiras colunas, Patrícia dirige uma crítica avassaladora aos vícios e às vicissitudes da vida social, da economia, da política e dos valores da sociedade brasileira. (...) Mais do que jornalismo, assemelha-se a uma ficção objetiva e a uma observação romanesca"(JACKSON, 2011: 37). Passados mais de cinco décadas de sua morte, Pagu é retratada como uma personagem midiática devido à sua trajetória ativista nas artes e na política. Inicialmente, silenciada; hoje, sua figura é símbolo de liberdade.

Pagu, nascida na longínqua década de 1910, já deslocava os lugares da mulher - no sexo, no casamento, na maternidade e na atuação pública: engravidou e abortou aos 14 anos; casou-se em segredo, separou-se pouco tempo depois e deixou, duranteas longas viagens ao exterior, o filho aos cuidados do pai ou da família; filiou-se a um partido político diversas vezes na ilegalidade, mudou de ideologia 
e revelou as contradições da agenda comunista; acreditou na arte e investiu no que pensava ser transformação social através do jornalismo e da literatura. A liberdade sexual, a maternidade tumultuada, a disposição para viagens comprometidas com suas ideias, o engajamento político e cultural, nenhuma dessas imagens pareciam adequadas para inspirar as mulheres brasileiras da década de 1970. (ROCHA; LANA, 2018: 25).

A trajetória destas escritoras e jornalistas demonstra que as mulheres participaram ativamente de diferentes fases da imprensa brasileira, seja em periódicos feministas, femininos ou na busca por espaços no jornalismo tradicional. O processo de ingresso das mulheres no jornalismo, entretanto, se concretiza somente a partir da segunda metade do século XX, quando é possível verificar mudanças no campo jornalístico, resultantes do processo de modernização da imprensa e da ampliação de veículos de comunicação (LUCA, 2011).

O protagonismo das mulheres foi fundamental para demarcar rupturas em um espaço reconhecidamente masculino e denunciar desigualdades, que persistem até a atualidade. Isso porque, conforme observa Marcia Veiga da Silva (2012: 503), "o jornalismo participa na formação de valores e na reprodução de relações de poder e produção de desigualdades que se fundam na cultura, incidindo não apenas nas relações entre os membros da "tribo", mas igualmente nos mapas de significados que resultam em desigualdades sociais".

\section{Mulheres biógrafas: Aspectos de uma narrativa}

Na tese defendida por Maciel (2018: 197), a jornalista Daniela Arbex afirma que deva existir um jeito feminino de narrar, "que transparece na escolha dos temas, das abordagens, do olhar e na forma como os personagens aparecem no livro-reportagem". No caso da produção do livro Holocausto brasileiro, o que mais a tocou foram os relatos das mães que não puderam alimentar seus próprios filhos. Na ocasião, Daniela vivenciava o mesmo momento. "E eu chegava em casa e ficava: “Meu Deus, como se arranca isso de uma mãe?” (MACIEL, 2018: 197). Isso pode ser percebido logo nas primeiras páginas de Furacão Elis, quando Regina Echeverría transparece comoção ao relatar a entrevista com a mãe da biografada. "Quando dona Ercy, desolada, levantou os óculos grossos para enxugar as lágrimas, me deu uma sensação de paralisia de afeto. Pareceu-me impossível não acariciar e confortá-la" (ECHEVERRÍA, 2012: 2).

Um conceito interessante que pode ser resgatado neste artigo para fundamentar o trabalho realizado por biógrafas é a definição de lugar de fala. $\mathrm{O}$ termo vem atrelado à palavra discurso,emprestada das ideias de Michel Foucault que, em outras palavras, nos atentam a "não pensar discurso como amontoado de palavras ou concatenação de frases que pretendem um significado em si, mas como 
um sistema que estrutura determinado imaginário social, pois estaremos falando de poder e controle" (RIBEIRO, 2017: 56). Assim, neste trabalho, avalia-se duas obras de jornalistas, mulheres, brancas, cujas protagonistas mulheres já são falecidas. Merece destaque o fato de Adriana Negreiros resgatar a figura de Maria Bonita negra e pobre - e dar voz a uma personagem silenciada que, através de suas ações, motivou gerações de mulheres a também se libertarem do jugo masculino. "Apesar de esconder o fato de que as cangaceiras eram submetidas a violências constantes na esfera doméstica e privada - embora vivessem ao ar livre do sertão -, essa mitificação não diminui o caráter transgressor da figura de Maria Bonita" (NEGREIROS, 2018: 16).

Regina Echeverría7 iniciou seu trabalho jornalístico no O Estado de S. Paulo, atuando na editoria de Esportes. Depois migrou para os impressos Jornal da Tarde, Veja, IstoÉ, Placar, Folha de S.Paulo, Caras, A Revista. Em televisão trabalhou na Abril Vídeo, TV Bandeirantes, RedeTV! e SBT. Seu primeiro livro é fruto da relação com a cantora Elis Regina, um contato que se iniciou em dezembro de 1975, quando cobriu matéria sobre o espetáculo "Falso Brilhante", ainda pelo JT. A primeira versão desta obra data de agosto de 1985, pela editora Nórdica. Depois dela, Echeverría publicaria Cazuza: Só as mães são felizes (1997) ${ }^{8}$, Verger: Um retrato em preto e branco (2002), Gonzaguinha \& Gonzagão: Uma história brasileira (2006) ${ }^{9}$, Mãe: Menininha do Gantois (2007), Sarney: A Biografia (2011), Sócrates Brasileiro (2013),A história da Princesa Isabel (2014) e Raimundo Fagner: Quem me levará sou eu (2019). Em virtude dos 30 anos do falecimento da cantora Elis Regina, a editora Leya publicou uma edição renovada do livro, mantendo o conteúdo original, com algumas atualizações. São 14 capítulos - com prefácio e epílogo inclusos, 240 páginas, sendo 66 delas dedicadas à discografia completa da cantora. "Afinal, resolvi contar a história de uma pessoa controvertida, uma mulher para quem a vida estava dividida em oito ou oitenta, amor ou ódio" (ECHEVERRÍA, 2012: 169-170).

Embora seja estreante na literatura, Adriana Negreiros é jornalista e trabalhou em redações como Playboy e Claudia. A pesquisa da autora resultou em 293 páginas separadas em 17 capítulos, além do prólogo e epílogo. Ao final da obra, Adriana menciona que enfrentou algumas dificuldades ao percurso; porém, não se deixou levar por falsas verdades:

7 Disponível em: http://www.reginaecheverria.com.br/perfil_15.html. Acessado em 29 jan. 2019.

8 A biografia inspiraria o longa Cazuza: O tempo não para. Lançado em 11 de junho de 2004, com direção Sandra Wernech e Walter Carvalho, o filme foi protagonizado pelo ator Daniel de Oliveira na pele do protagonista, além de Marieta Severo, como Lucinha Araújo. Disponível em: https://globofilmes.globo. com/filme/cazuzaotemponaopara/. Acessado em 14 mai. 2019.

9 A obra serviria de roteiro para o filme Gonzaga: De pai pra filho, estreado em 26 de outubro de 2012, ano do centenário de nascimento do "Rei do baião". Dirigido por Breno Silveira, a cinebiografia foi protagonizada pelos atores Land Vieira, Chambinho do Acordeon e Adelio Lima no papel de Luiz Gonzaga e Alison Santos, Giancarlo diTomazzio e Júlio Andrade interpretando Gonzaguinha. Disponível em: https://globofilmes.globo.com/filme/gonzagadepaiprafilho/. Acessado em 17 jan. 2019. 
Embora tenha feito uso constante do ceticismo indissociável da prática jornalística, em nenhum momento me permiti duvidar das versões apresentadas por Dadá, Sila, Inacinha, Otília e tantas outras que foram obrigadas a largar suas famílias para se tornarem cangaceiras. Não compreendo como se possa conceber que crianças ainda às voltas com bonecas escolhessem viver ao relento, subjugadas por homens extremamente violentos, submetidas a fome, sede e risco constante de morte.Colocar em suspeição a versão das cangaceiras faz parte do mesmo padrão e da mesma lógica que insiste em desqualificar os relatos das mulheres quando violentadas. Uma distorção atávica, que transforma vítimas em culpadas e procura encontrar no comportamento feminino as alegadas razões para justificar a opressão. (NEGREIROS, 2018: 249-250).

Elis Regina Carvalho Costa e Maria Gomes de Oliveira, a Maria de Déa - o sobrenome Bonita viria apenas após o seu falecimento - eram personagens antagônicos; porém, complementares. A primeira, defendia a independência feminina; a segunda, submissa, dominada, mas com poder de influência sobre o companheiro. A construção narrativa destas duas mulheres, nas biografias referenciadas, é desenvolvida no próximo tópico, a partir de elementos baseados nos estudos de gênero.

\section{Protagonistas femininas: Arepresentaçãodas mulheres biografadas}

Após compreender a atuação das mulheres no jornalismo, especialmente na produção de biografias, e a pertinência da noção de lugar de fala para a presente pesquisa, busca-se refletir sobre a constituição das personagens na literatura brasileira. Para isso, se fazem presentes os estudos de Gerda Lerner (1990), Sueli Carneiro (2002), Regina Dalcastagnè (2012) e AngelaDavis (2016), que trazem importantes contribuições a respeito dos estereótipos das mulheres na escrita.

Lerner (1990: 57) reflete a respeito da origem do patriarcado, processo que, segundo ela, levou 2.500 anos."A sexualidade das mulheres, isto é, suas capacidades e serviços sexuais e reprodutivos, tornou-se uma mercadoria antes mesmo da criação da civilização ocidental"ı. As mulheres carregavam um valor de troca e foram consideradas como o primeiro acúmulo de propriedade privada. Enquanto homens eram apenas trabalhadores, as mulheres também trabalhavam, além de prestarem serviços sexuais e reprodutivos. Para Lerner, o sistema patriarcal só poderia funcionar graças à cooperação das mulheres, por meio da privação de ensino, repressão e discriminação no acesso aos recursos econômicos. Ou seja, as mulheres foram "moldadas psicologicamente para internalizar a ideia de sua própria inferioridade" (LERNER, 1990: 6o). Pelo termo patriarcado, a autora interpreta que é uma relação

10 Versão original: "La sexualidad de las mujeres, es decir, sus capacidades y serviciossexuales y reproductivos, se convirtióen una mercancía antes incluso de lacreación de lacivilizaciónoccidental”. 
entre aquele que domina e o outro, inferior. Assim, até mesmo na família, a relação entre pais/irmãos e mães/irmãs era bem pontuais. "A subordinação dos filhos do sexo masculino à dominação parental é temporária; dura até eles mesmos se tornarem chefes de família. A subordinação das filhas e da esposa é para toda a vida” (LERNER, 1990: 60) ${ }^{11}$. Tal situação poderá ser ilustrada pelo trecho a seguir, a respeito da viuvez no cangaço.

Como regra, depois da morte de seus maridos, as mulheres ficavam à disposição dos outros cabras, como um patrimônio sem herdeiro certo. Um cangaceiro solteiro poderia, se quisesse, pegar a moça para ele. Se houvesse mais de um interessado, que resolvessem a disputa entre si, amigavelmente. Caso não despertasse o interesse de ninguém, o mais recomendável era que fosse morta, pois, caso voltasse para casa, poderia entregar os segredos do grupo para a polícia. A presença de mulheres solteiras era rigorosamente proibida no bando. Só ficava ali quem tinha dono. (NEGREIROS, 2018: 124).

Como observado, essa preponderância masculina apenas reforça a transformação da mulher em mercadoria, tratada como um objeto negociável entre os pares daquele determinado nicho social. Chama a atenção a maneira como Lerner (1990) pensa o contexto histórico. Para ela, infere-se que a primeira forma de dominação é o homem sobre a mulher e, por consequência, essa superioridade transparece no jeito de contar a narrativa. Iracema era caracterizada como a virgem dos lábios de mel, aquela quem enfeitiçava o colonizador (ALENCAR, 1995). Isaura era uma escrava que fugia do padrão de sociedade colonial, tão formosa e linda que “(...) ninguém dirá que gira em tuas veias uma só gota de sangue africano" (GUIMARÃES, 1998: 14). Rita Baiana despertava desejos no cortiço, já que “(...) era a cobra verde e traiçoeira, a lagarta viscosa, a muriçoca doida, que esvoaçava havia muito tempo em torno do corpo dele, assanhando-lhe os desejos, (...) picando-lhe as artérias, para lhe cuspir dentro do sangue uma centelha daquele amor setentrional"(AZEVEDO, 2008: 88). Pelo seus olhos de ressaca, Capitu foi taxada como adúltera (ASSIS, 2000). Na ficção brasileira, mulheres não existiam ou, quando eram lembradas, os estereótipos vinham à tona. Ribeiro (1996) pesquisa sobre as personagens femininas constituídas nas obras de José de Alencar e Machado de Assis. O autor sintetiza a construção social delas em virtude do ambiente descrito:

11 Versão original: "El término describe la relación entre un grupo dominante, al que se considera superior, y un grupo subordinado, al que se considera inferior, enla que la dominación queda mitigada por las obligaciones mutuas y los deberes recíprocos. (...) En la familia patriarcal, las responsabilidades y las obligaciones no están distribuidas por un igual entre aquellos a quienes se protege: la subordinación de los hijos varones a la dominación paterna es temporal; dura hasta que ellos mismos pasan a ser cabezas de familia. La subordinación de las hijas y de la esposa es para toda la vida". 
As heroínas civilizadas, todas elas, surgem na cena dos romances movimentando-se nas altas rodas da sociedade. (...) Qualificam-se sempre como as rainhas dos salões, mimetizando na sociabilidade elegante a hierarquia do poder político. Seus dramas restringemse à esfera do matrimônio e sua existência divide-se em dois tempos: nos salões, antes do casamento, e em sua casa, depois dele. Sua educação restringe-se a algumas prendas sociais como ler e escrever, fazer algumas contas, conhecer francês, tocar piano, cantar, ler literatura e bordar. Nada mais se lhes exige, além de ter algum pequeno capital para as despesas da conversação nas salas elegantes. Estão todas destinadas a serem esposas e não donas de casa. O trabalho - reservado para a escravaria e para os criados, que não entram na história - está ausente de seu mundo. $\mathrm{O}$ trabalho, os negócios e a política, entenda-se. Sua única e grande finalidade é casar e serem mães. E os exemplos das que não o conseguem são sempre tangenciais ao dramático. (RIBEIRO, 1996:390).

Dalcastagnè (2012: 125) contribui com essa análise ao afirmar que a "representação do espaço da mulher, portanto, dá-se, sobretudo, pelo seu enclausuramento no âmbito doméstico, a esfera privada”. Esse é apenas um dos apontamentos da pesquisa de Dalcastagnè, que estudou 258 romances publicados entre 1990 a 2004 e identificou, ao total, 1245 personagens "importantes". Sua conclusão chegou que 773 , ou seja, 62,1\% dos personagens são masculinos; em contrapartida dos $471(37,8 \%)$ do sexo feminino. Essa visibilidade se torna maior quando avalia a posição da narrativa. "Além de serem minoritárias nos romances, as mulheres têm menos acesso à voz - isto é, a posição de narradoras - e ocupam menos as posições de maior importância" (DALCASTAGNÈ, 2012: 165).

Quanto à cor da personagem no romance brasileiro contemporâneo, a predominância é branca, se comparar os 7,9\% dos negros, 6,1\% mestiços, 1,2\% indígenas e $0,6 \%$ orientais. A pesquisa ainda identifica que "o contingente de protagonistas mulheres brancas equivale a $28,7 \%$ do total de protagonistas brancos, de ambos os sexos, mas as protagonistas mulheres negras equivalem a apenas 15\% dos protagonistas negras de ambos os sexos" (DALCASTAGNÈ, 2012: 176). Se resgatarmos apenas esse dado, poderemos aqui refletir sobre como essa pequena representatividade ilustra de que forma o racismo contaminou a sociedade. A mulher negra e pobre carrega uma tripla 'anomalia', na maioria das vezes constituída de dominação. Na sociedade escravocrata, as 'mulheres de cor' eram tidas somente como reprodutoras. "Quando era lucrativo explorá-las como se fossem homens, eram vistas como desprovidas de gênero; mas, quando podiam ser exploradas, punidas e reprimidas de modos cabíveis apenas às mulheres, elas eram reduzidas exclusivamente à sua condição de fêmeas" (DAVIS, 2016: 19). Soma-se a isso o fato da história ser sempre uma batalha pelo registro. Geralmente, de quem venceu, quando anula e envergonha o derrotado. No regime escravista, "o estupro, na verdade, era 
uma expressão ostensiva do domínio econômico do proprietário e do controle do feitor sobre as mulheres negras na condição de trabalhadoras" (DAVIS, 2016: 20). Na obra a respeito de Maria Bonita, a jornalista identifica essa situação:

Para uma jovem estuprada por cangaceiro nos anos 1930 no sertão do Nordeste não havia muito a fazer além de maldizer a própria sorte. Denunciar o crime às forças volantes seria duplamente temerário. (...) A perda da virgindade também condenava a jovem sertaneja ao preconceito. Deflorada, tinha mais dificuldade para conseguir casamento. De uma futura esposa, esperava-se pureza absoluta. (NEGREIROS, 2018: 53-54).

Carneiro (2002) acompanha esse viés ao caracterizar o assédio sexual como violência de gênero. Para ela, na literatura, "a mulher negra será retratada como exótica, sensual, provocativa, enfim, como fogo nato. Tais características chegam a aproximá-la de uma forma animalesca, destinada exclusivamente ao prazer sexual" (CARNEIRO, 2002: 171). Sendo assim, pelo apetite que causava nas fantasias masculinas, as negras não conseguiam emprego, e se viam reféns do destino "como mucama, ama-de-leite, dama de companhia, ou, então, prostituindo-se, aproveitando-se de sua disseminada fama de 'boa de cama”' (CARNEIRO, 2002: 173). Atrelado a isso, a mulher branca era associada à esposa calada, submissa, sofredora. Entretanto, conseguia ser autoritária quando o marido não estava presente.

A gravidez é outro tópico fundamental no tocante à construção de representações do sexo feminino. Enquanto aos 19 anos Elis Regina realizou um aborto na sua primeira gravidez ${ }^{12}$, Maria Bonita deu à luz uma única filha - Expedita; porém, a criança precisou ser separada da mãe e do bando. Situações diferentes, que podem ser avaliadas através dos estudos de gênero. A liberdade de decidir, sozinha, o seu próprio destino, foi uma marca primordial de Elis desde a infância. Não seria diferente na transição da adolescência para a vida adulta. A socióloga israelense Orna Donath (2017: 51) opina: “Todo ser humano de fato nasce de uma mulher, mas nenhuma mulher nasce mãe: que as mulheres carregam os descendentes humanos pode ser um fato, mas isso não obriga as mulheres a se comprometerem com os cuidados (...) que essa relação exige”. Ofragmento da biografia de Elis, abaixo, ilustra o debate sobre a autonomia feminina:

Mas não foi por isso que Solano Ribeiro e Elis Regina terminariam o namoro. Algum tempo depois, quando já havia trocado o Rio por São Paulo, ela engravidou e resolveu fazer um aborto. Segundo Solano Ribeiro, foi aí que tudo acabou mesmo: Ela ficou grávida, fez o aborto e não me disse nada na hora. Disse depois. (ECHEVERRÍA, 2012: 15).

12 Elis Regina teria três filhos: João Marcello Bôscoli (1970), fruto do casamento com o compositor Ronaldo Bôscoli; Pedro Mariano (1975) e Maria Rita (1977), ambos resultados do relacionamento com o compositor Cesar Camargo Mariano. 
O segundo trecho selecionado traduz a brutalidade de como a separação forçada ocorria no solo árido do Nordeste. Para interpretar esse caso, busca-se explicação em Elisabeth Badinter (1981). A filósofa e historiadora francesa lembra que, no século XVIII, mães urbanas enviavam os filhos para a zona rural a fim de beneficiar a saúde dos pequenos. Em outras palavras, por mais que houvesse saudade pela distância, "a entrega do filho a uma ama-de-leite para ser criado deixa de ser sinal de desinteresse pela criança afastada, tornando-se o contrário, a ilustração suprema do mais puro altruísmo" (BADINTER, 1981: 12). Conforme o excerto:

Como não utilizavam métodos contraceptivos e precisavam estar disponíveis para seus homens, as cangaceiras podiam pegar barriga a qualquer momento. Uma vez que os filhos nascessem, deveriam passá-los adiante, na primeira oportunidade. Frágeis, recémnascidos não combinavam com a bruta rotina do cangaço, entre espetadas de sol e chuvas de tiro. Ademais, o choro denunciava a presença dos bandoleiros para as forças oficiais. (NEGREIROS, 2018: 63).

Através da leitura de Furacão Elis, observam-se comportamentos em que dicotomias da protagonista se mesclam de maneira abrupta: insegura e explosiva, infantil e madura, ingênua e complicada. Da mesma forma que pregava a independência feminina - fato ilustrado no momento que Elis assina o desquite junto a Ronaldo Bôscoli em maio de 1972, numa época em que a lei do divórcio seria oficializada apenas em 1977 -, a biografada também conseguia ser afável com quem lhe despertasse segurança. Todavia, esbarrava na relação familiar. Logo no início do livro, Regina Echeverría demonstra que a relação de Elis seria tensa, principalmente com o pai. "O dinheiro da filha veio a calhar, mas criou o primeiro conflito familiar, que se agravaria com o passar dos anos e o dinheiro conquistado. Elis Regina ainda não tinha 14 anos e já ganhava mais do que o pai” (ECHEVERRÍA, 2012: 6). Mais adiante, a vergonha masculina era evidente:

Seu Romeu, sem emprego, fez da carreira da filha um bico. Passou a cuidar dos cachês, acertar os contratos para shows, receber, como se fosse um empresário. Mas Elis, que tinha o controle econômico sobre a família, sentia-se poderosa. Cobrava do pai e do irmão que se virassem e cuidassem a própria vida. Ao mesmo tempo, alimentava a dependência, dando-lhes dinheiro, como se fosse impossível para ela suportar a culpa de estar bem de vida e saber que a família passava necessidade. (ECHEVERRÍA, 2012: 16).

No trabalho sobre a construção do masculino, Welzer-Lang (2001, p. 461) aponta que “(...) os homens dominam coletiva e individualmente as mulheres. Esta dominação se exerce na esfera privada ou pública e atribui aos homens privilégios materiais, culturais e simbólicos". Em seguida, o sociólogo francês encerra a ideia. "A 
opressão das mulheres pelos homens é um sistema dinâmico no qual as desigualdades vividas pelas mulheres são os efeitos das vantagens dadas aos homens" (WELZERLANG, 2001: 461).

Estas disputas transparecem em várias passagens das biografias analisadas, que abordam aspectos da vida e da personalidade das personagens, conjugando o protagonismo e a autonomia representados em suas histórias com as imposições de uma sociedade desigual e hierárquica.

\section{Considerações finais}

Este artigo tem como objetivo reconhecer as vozes de duas mulheres jornalistas no mercado livreiro que se dedicaram a recontar histórias de protagonismo feminino. Enquanto Regina Echeverría escreveu a história da MPB sobre a perspectiva de Elis Regina, Adriana Negreiros proporcionou um novo fôlego para a história do cangaço com Maria Bonita. Furacão Elis foi a primeira biografia feminina escrita por uma jornalista mulher e Maria Bonita, até então, a mais recente, o que permite vislumbrar o percurso das biógrafas em distintas temporalidades.

Para isso, foi levado em conta um panorama do biografismo jornalístico no Brasil, desde Raimundo Magalhães Jr, passando por Alberto Dines e o boom de vendagem na década de 1990. Além disso, discute-se a inserção das mulheres na imprensa, trazendo breves características de Rachel de Queiroz e a própria Patrícia Galvão. Por fim, Elis Regina e Maria Bonita foram estudadas pelo viés das pesquisas de Badinter (1981), Carneiro (2002), Davis (2016), Donath (2017) e Lerner (1990), correlacionadas com trechos das biografias.

Diante destas escolhas, pode-se avaliar o contexto do momento de escrita. Se na década de 1980 não era tão comum observar os estudos de gênero refletidos em obras biográficas, o livro Maria Bonita: Sexo, violência e mulheres no cangaço já apresenta aspectos de empoderamento feminino ao longo das páginas.

Ademais, reitera-se a importância desse tipo de estudo ao unir jornalismo, biografias e mulheres, sendo elas pela perspectiva autoral ou de personagem. A interação entre gênero, raça, maternidade e outros marcadores presentes nas biografias revela um conhecimento que agrega aos estudos literários bem como aos estudos do biografismo, em que foi possível observar influências de aspectos relativos às representações de gênero na confecção de obras de caráter não-ficcional. Por fim, tanto nos exemplos ilustrados da ficção quanto nas duas obras analisadas os estereótipos estão presentes e os estudos de gênero permitem decifrar as razões pelas quais essas imagens femininas permanecem distorcidas e estigmatizadas. 


\section{Referências bibliográficas}

ALENCAR, José de. Iracema. São Paulo: Ática, 1995.

ANDRADE, Mariza Guerra. Anel encarnado: Biografia e história em Raimundo Magalhães Junior. Belo Horizonte: Autêntica, 2013.

ARBEX, Daniela. Cova 312: A longa jornada de uma repórter para descobrir o destino de um guerrilheiro, derrubar uma farsa e mudar um capítulo da história do Brasil. São Paulo: Geração Editorial, 2015.

. Holocausto brasileiro: genocídio: 60 mil mortos no maior hospício do Brasil. São Paulo: Geração Editorial, 2013.

. Todo dia a mesma noite.Rio de Janeiro: Intrínseca, 2018.

ASSIS, Machado de. Dom Casmurro. São Paulo: Ática, 2000.

AZEVEDO, Aluísio. O cortiço. Campinas: Komedi, 2008.

BADINTER, Elisabeth. Um amor conquistado: Omito do amor materno. Rio de Janeiro: Nova Fronteira, 1981. p. 9-23 (Prefácio à Edição de Bolso e Prefácio).

BRUM, Eliane. A vida que ninguém vê.Porto Alegre: Arquipélago Editorial, 2006. . O olho da rua. Rio de Janeiro: Globo Livros, 2008.

BULHÕES, Juliana; SOBRAL, Gustavo Leite. Rachel de Queiroz, jornalista. In: Estudos de Jornalismo e Mídia, v. 14, n. 1. p. 39-50, 2017.

CARNEIRO, Sueli. Gênero e raça. In. Gênero, democracia e sociedade brasileira. São Paulo: Fundação Carlos Chagas, 2002.

CARVALHO, Kátia de. A imprensa feminina no Rio de Janeiro, anos 20: Um sistema de informação cultural. Ciência da Informação - v. 24, n.1, 1995.

CATALÃO JR, AntonioHeriberto. Jornalismo best-seller: O livro-reportagem no Brasil contemporâneo, 2010. 252 f. Tese (Doutorado em Linguística e Língua Portuguesa) Universidade Estadual Paulista “Júlio de Mesquita Filho”, Araçatuba, 2010.

COSTA, Cristiane. Pena de Aluguel: Escritores jornalistas no Brasil, 1904-2004. São Paulo: Companhia das Letras, 2005. 
DALCASTAGNÈ, Regina. Literatura brasileira contemporânea: Um território contestado. Vinhedo: Editora Horizonte, 2012.

DAVIS, Angela. Mulheres, Raça e Classe. São Paulo: Boitempo, 2016.

DONATH, Orna. Mães Arrependidas: Uma outra visão da maternidade. Rio de Janeiro: Civilização Brasileira, 2017.

DUARTE, Constância Lima. Imprensa feminina e feminista no Brasil. Século XIX: Dicionário ilustrado. Belo Horizonte, Autêntica Editora, 2016.

ECHEVERRÍA, Regina. Furacão Elis. São Paulo: Leya, 2012.

GALVÃO, Walnice Nogueira. A voga do biografismo nativo. In: Estudos Avançados. Vol.19 n.55. São Paulo Set./Dez. 2005. p.350-366.

GUIMARÃES, Bernardo. A escrava Isaura. São Paulo: Ática, 1998.

JACKSON, Kenneth. Uma evolução subterrânea: O jornalismo de Patrícia Galvão. Revista do Instituto de Estudos Brasileiros, n.53 (2011). Disponível em: http://www. revistas.usp.br/rieb/article/view/34683/37421. Acesso em 29 jan. 2019.

LENER, Gerda. El origem del Patriarcado. In: La creaciondel patriarcado. Ed. Crítica, Barcelona, 1990. Disponível em:https://www.antimilitaristas.org/IMG/pdf/la_ creacion_del_patriarcado_-_gerda_lerner-2.pdf. Acesso em 29 jan. 2019.

LUCA, Tânia Regina de. "A grande imprensa na primeira metade do século XX". In: MARTINS, Ana Luiza e LUCCA, Tânia Regina de. História da Imprensa no Brasil. São Paulo: Contexto, 2011. p. 149-175.

MACIEL, Alexandre Zarate. Narradores do contemporâneo: Jornalistas escritores e o livro-reportagem no Brasil, 2018. 310 f. Tese (Doutorado em Comunicação) Universidade Federal de Pernambuco, Recife, 2018.

MUZART, ZahidéLupinacci. Uma espiada na imprensa das mulheres no século XIX. Revista Estudos Feministas. CFH/CCE/UFSC. Vol. 11, n. 1, 2003. p. 225-233.

NEGREIROS, Adriana. Maria Bonita: Sexo, violência e mulheres no cangaço. Rio de Janeiro: Objetiva, 2018.

PERROT, Michelle. As mulheres ou os silêncios da história. Bauru: Edusc, 2005.

RIBEIRO, Djamila. O que é lugar de fala?.Belo Horizonte: Letramento, 2017. 
RIBEIRO, Luis Filipe. Mulheres de papel: Um estudo do imaginário em José de Alencar e Machado de Assis. Niterói. Eduff, 1996.

ROCHA, Everardo; LANA, Lígia. Imagens de Pagu: Trajetória midiática e a construção de um mito. Cadernos Pagu. n.54, Campinas (2018). Disponível em: http://www.scielo. br/pdf/cpa/n54/18o9-4449-cpa-18094449201800540016.pdf. Acesso em 29 jan. 2019.

SILVA, Marcia Veiga da. Gênero: Um ingrediente distintivo nas rotinas produtivas do jornalismo. Estudos de Jornalismo e Mídia, Florianópolis, v. 9, n. 2, p. 490- 505, juldez, 2012.

VIEIRA, Karine Moura. Do fazer um saber:A construção do biografar. O discurso de autoria sobre a prática jornalística na produção de biografias por jornalistas brasileiros, 2015. 213 f. Tese (Doutorado em Ciências da Comunicação) - Universidade do Vale do Rio dos Sinos, São Leopoldo, 2015.

VILAS BOAS, Sérgio. Biografia e biógrafos: Jornalismo sobre personagens. São Paulo: Summus, 2002.

WELZER-LANG, D. A construção do masculino: A dominação das mulheres e homofobia. Estudos Feministas. v.9, Florianópolis (2001). Disponível em: http://www. scielo.br/pdf/ref/vgn2/8635.pdf. Acesso em 29 jan. 2019.

Recebido em 16/o4/2019.

Aceito em 01/o6/2020. 